\title{
Otorhinolaryngology of the University of São Paulo Medical School
}

\section{Ricardo Ferreira Bento}

The Otorhinolaryngology of the University of São Paulo (USP) Medical School has been established since USP's Medical School was founded in 1912, and since then this renowned specialization has contributed to the technical, scientific and professional training of students of this traditional School and professionals from this and other Universities in Brazil and abroad, with its Undergraduate Courses in Medicine, Medical Residency, Specialized Complementary Programs (Fellowship), Professional Training Program for Foreign Doctors, Short and Long Term Practical Training Program, Researcher Program, Volunteer Medical Program and stricto sensu Postgraduate Courses (Masters and PhD).

It has and still does contribute to the training of professors in almost all Medical Courses in Brazil and many abroad. Hundreds of Otorhinolaryngology services and thousands of professionals in Brazil and abroad. It also contributes for the technical, scientific and professional training of students of the undergraduate program in speech-language pathology, physiotherapy and occupational therapy, as well as Specialization Courses to professionals that have already graduated in these areas (Speech Therapy, Physiotherapy)

It conducts intense activity related to scientific research with numerous lines of research undertaken by its faculty and students, being undoubtedly the main center for basic and clinical experimental research in Brazil and in Latin America, and one of the largest in the world in the field of Otorhinolaryngology. At the example of all Departments of USP, the Otorhinolaryngology Department aims to offer teaching, research and assistance service to the community, and does so very efficiently.

The Professors who were in charge, as well as the current chairman and many of its teachers and researchers are renowned specialists at the national and international levels.

Otolaryngology was ministered under the beginning of the FMUSP. In 1914, Professor Henrique Lindenberg (Figure 1) was hired as Otolaryngology Professor. Based on the new regulations, all fundamental disciplines had to be taught by full-time and fixed professors, considered as titular professors Arnaldo Vieira de Carvalho invited Henrique Lindenberg, a pharmacy graduate professor, to Head the department. His assistants during his time as Professor were: Roberto Oliva; Adolpho Schmidt Sarmento (first assistant); Mário Ottoni de Rezende; Francisco Hartung; Silvestre Passy Ângelo Mazza (who later became professor and regent of the otolaryngology discipline at Escola Paulista de Medicina), Silvio Ognibene, Antônio Vicente de Azevedo e Ernesto Moreira. Professor Schmidt Sarmento, a Professor of the Medical School, took tenure of the Otolaryngology

Full Professor of the Otorhinolaringoloy Discipline of the Department of Otorhinolaringology and Ophthalmology of the University of São Paulo's Faculty of Medicine (Departamento de Otorrinolaringologia e Oftalmologia da Faculdade de Medicina da Universidade de São Paulo - FMUSP).

Mailing address: Av. Dr. Enéas de Carvalho Aguiar, 255 - 6º andar. CEP: 05403-00 - São Paulo, SP, Brasil. E-mail: rbento@gmail.com 
Discipline of the Medical School upon professor Lindenberg's absence, who was traveling to Europe between 1923 and 1926 due to health issues.

Henrique Lindenberg headed the department until his demise, in 1928.

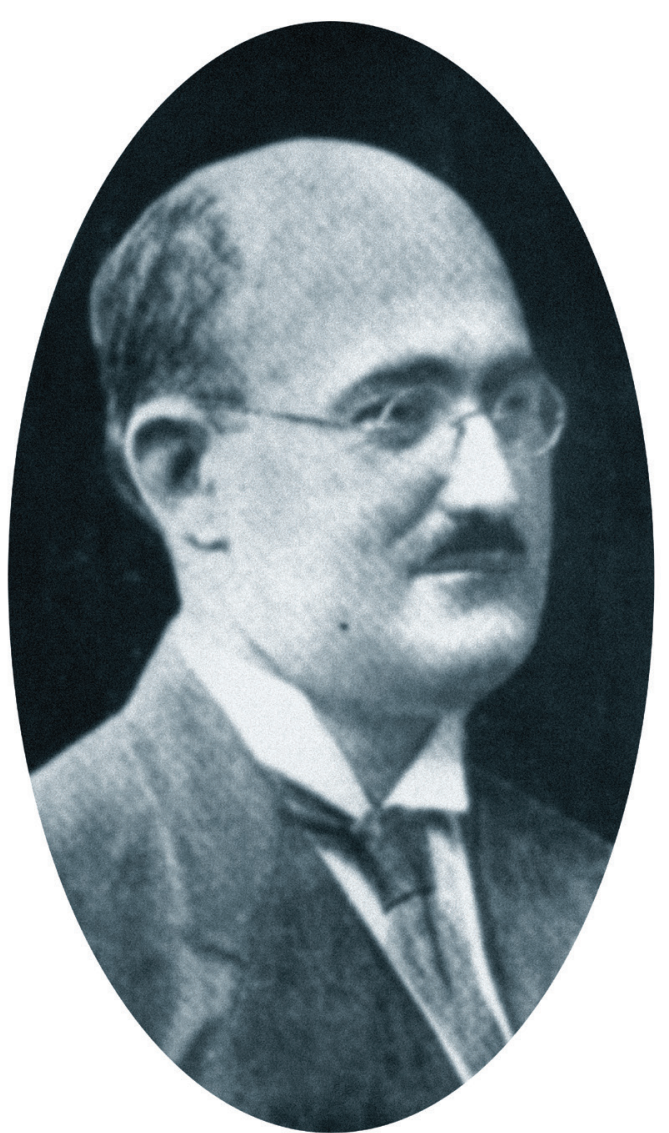

Figure 1. Professor Henrique Lindenberger, first professor at 1915 and 1929

In 1928, after Lindenberg's demise, the Chair of Otolaryngology was vacant. Professor Antonio de Paula Santos, professor of Pathology at the School, requested a transfer to the Chair of Otolaryngology, since he practiced Otolaryngology in his private practice, and the Medical School did hold a selection process.

Professor Paula Santos' assistants were: Raphael da Nova; José Freire de Mattos Barreto; Jayme Ribeiro de Campos; Plínio Mattos Barreto* Rubens de Brito and Antonio Prudente Correa.

At this time a original idea for peroral endoscopic service organization appeared in 1934, when a group of illustrious Otolaryngologists, gathered in the ORL Department of Associação Paulista de Medicina, decided it was time to organize an exclusive section for the practice of modern bronchoesophagology. It was created in the Otorhinolaryngological Department.

The Hospital das Clínicas (HC) was inaugurated on April 19, 1944, and Santa Casa Medical School's Services were relocated to the new $\mathrm{HC}$ gradually over the following years. ENT relocation to HC took place in 1945.

Within the hospital complex, the entire Otolaryngology Department was based on the sixth floor of the south and central wings, where it remains to this day.

In addition to the infirmary ward, the department included the outpatient clinic, administrative offices, library, assembly room, emergency room, and an exclusive surgery center with 3 rooms attached to the infirmary ward. The department has shared the sixth floor with Ophthalmology since the beginning.

In 1956, Raphael da Nova replaced Professor Antonio Paula Santos, after the latter's retirement.

It is important to note that the Department grew considerably after the $\mathrm{HC}$ was inaugurated, since its operations involved hiring dozens of physicians to work at the Hospital.

\section{The Oral and Maxillofacial service was in the ENT Department headed by Prof. Gino de Lascio}

The FMUSP Phonoaudiology Course was inaugurated in the Otolaryngology Department and organized at that time by Prof. Dr. Paulo Américo Morganti, phoniatrist and Edigar Resende de Almeida. Such partnership with the phonoaudiology is crucial for the otolaryngology area regarding audiology and diagnosis/ rehabilitation of deafness and labyrinth diseases, treating and rehabilitating voice diseases and laryngectomy patients, mouth breathers, facial deformities; speech therapy is currently regarded as a health profession always associated to ORL, which is the case of the Otolaryngology Division of FMUSP's Hospital das Clinicas, operating in complete synergy with dozens of speech therapists of the ORL staff.

In 1969, after the retirement of Professor Raphael da Nova, Professor Lamartine Junqueira Paiva that was then appointed as the Titular Professor of the discipline.

In 1989, with the mandatory retirement of Prof. Dr. Lamartine Junqueira Paiva, Professor Aroldo Miniti, was 
selected and took over the Discipline, where he remained as Titular Professor until 2006, the year of his mandatory retirement.

In 2006, after professor Aroldo Miniti retired, Professor Ricardo Ferreira Bento took over the post of Titular Professor, after a selection process held on December 6, 2006.

Ricardo Ferreira Bento, the actual professor, graduated in 1978 and performed a residency in Otolaryngology at Hospital das Clinicas of the Medical School of Universidade de São Paulo (University of São Paulo - FMUSP). He performed a two-year fellowship program with Professor Ugo Fisch, in University of Zurich, Switzerland, where he trained and brought to Brazil the modern otoneurosurgery technique.

In 2006, he was appointed the Titular Professor of the Otolaryngology Discipline. In 2007, he was elected head of the FMUSP Ophthalmology and Otolaryngology Department.

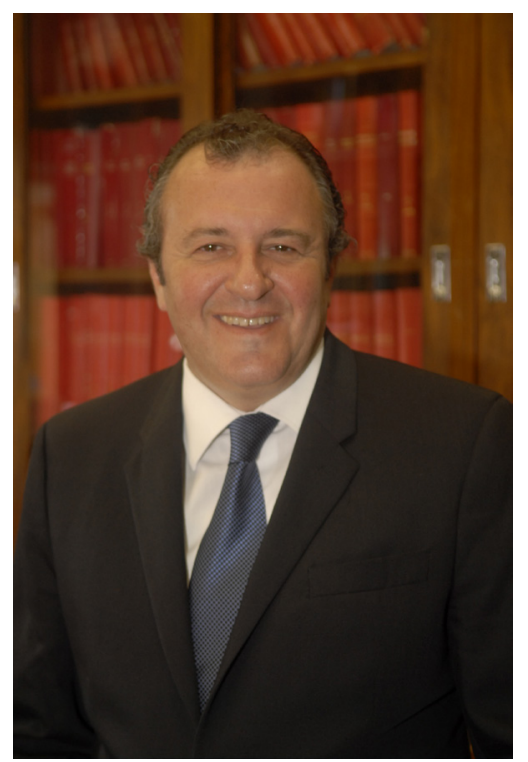

Figure 2. Prof Ricardo Bento, actual full professor

\section{Ricardo Bento had a intense activity in the specialty}

He published over 300 articles in national and international magazines, receiving the Top Prize of the American Academy of Otolaryngology and the French society of Otolaryngology for his relevant services in Otorhinolaryngology. In 2013, he won the national award for theses from Coordenação de Aperfeiçoamento de
Pessoal de Nivel Superior (CAPES) of the Ministry of Education for coordinating the thesis regarding facial nerve regeneration with stem cells, which had also won the award of best scientific project at the World Otolaryngology Congress held in South Korea, in 2013.

Ricardo Ferreira Bento participated in over 600 conferences and courses across 45 countries. He organized the World Otolaryngology Congress in São Paulo. He was editor of the Brazilian Journal of Otolaryngology and is the author of numerous reference books, which were translated into several languages.

Since he took the Chair of Otolaryngology, he works for the internationalization of the Department, using his international prestige to promote the Clinic abroad, receiving trainee doctors from all around the world and participating in important global decisions in the area.

He conceived the CERTOO - Eyes and Ears Treatment and Rehabilitation Center, which along with professor Remo Suzanna Jr., Titular of the Ophthalmology Discipline, has been designed along with the Boards of Hospital das Clínicas and the São Paulo State Government, to develop research, education and medical care to the community within the Ophthalmology and Otolaryngology areas.

Always ahead of innovations and the objectives of the University, he spearheaded the development of a generic auditory prosthetic which will generate great income for Under his leadership, there is no doubt that the Clinic's diversity and excellence have consolidated it as one of the most important otolaryngology services worldwide.

His assistants at FMUSP were: Ossamu Butugan, Edigar Resende de Almeida, Silvio Antonio Monteiro Marone, Richard Louis Voegels, Luiz Ubirajara Sennes, Tanit Ganz Sanchez, Domingos Hiroshi Tsuji and Rubens Vuono de Brito Neto.

Traditionally, this Department has active participation in congresses and symposia related to the specialty around the world. It presents high-level technical and scientific production, publishing books and articles in journals in Brazil and abroad. Its basic and experimental research represented a significant contribution to the study of pathogenesis, diagnosis and treatment of numerous ENT-related diseases. 


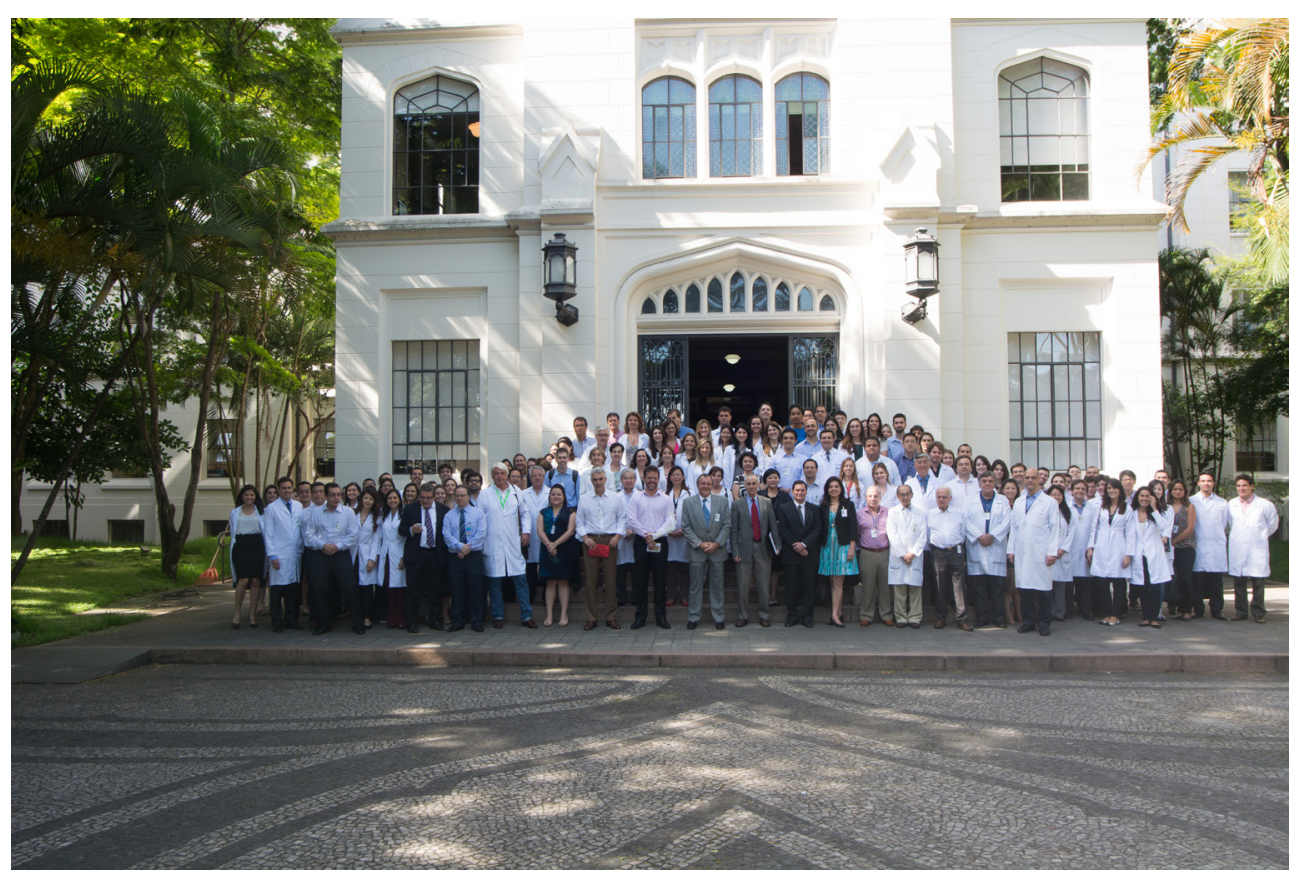

Figure 3. Members of the Otorhrinolaryngology discipline

The Otorhinolaryngology Discipline at FMUSP is currently taught in the Otorhinolaryngology theoreticalpractical course during the $3^{\text {rd }}$ year of the Undergraduate Program of the University of São Paulo Medical School for 180 (one hundred and eighty) students, divided into two classes. The practical lessons are arranged in groups of 8 students, giving them the opportunity of learning the theory and daily practice in outpatient Otorhinolaryngology service and all the speech therapy support.

During the fifth year, FMUSP students go through the Clinic at a system similar to a boarding school, where groups of 12 students rotate through several sectors of the Clinic.

Recalling the history of Otorhinolaryngology of Hospital das Clinicas is like reporting the history of Otorhinolaryngology in São Paulo.

From gouges and hammers to motors and drills; from tuning forks to audiometers, progress has also been significant related to front mirror lighting to photophores and their lenses that Otorhinolaryngologists were highly excited about, and soon after 1958 the surgical microscope was adapted, which seemed to be very promising. From nasal speculums to modern endoscopes, from laryngeal mirrors to nasopharyngoscopes came the most significant progress in Otorhinolaryngology at Hospital das Clinicas, which always sought to keep updated, following the progress of other areas, such as computed radiology and tomography, and finally MRI. Thus, the
Otorhinolaryngology department kept - and still keeps - its good reputation nationally and internationally, which is the philosophy of FMUSP Hospital das Clínicas.

The first transplant done at Hospital das Clinicas was tympanic membrane, held at the Otorhinolaryngology Clinic in 1964.

This Discipline is expected to continue its tradition related to professional, technical and scientific training at undergraduate and graduate levels to professionals from all over the country, to renew the teaching and research staff from this University and other Institutions in Brazil and abroad. The continuity and improvement of the lines of research and scientific technical production will always be equally sought goals. The scope and implementation of the research activities in the Discipline allow the practical exercise of a scientific-educational model aimed especially to the effective implementation of science coupled with technological development. The Discipline has preserved and directed results to reach its excellence ideal, associated to the production of innovations and technological improvements relevant to and guided by light of the service provided to the social universe. The provision of service to the community translates to thousands of patients cared for annually, and examinations and surgeries ranging from the most simple to the most complex, becoming one of the world's most advanced centers for the treatment of diseases of the ear, nose and throat. 